\title{
Evaluating the Health of an Urban River Combining DPSIR Framework and an Improved Fuzzy Matter-Element Extension Model: a Case Study from the Jinshui River
}

\author{
Han Han ${ }^{1}$, Kaize Zhang ${ }^{1 *}$ Jinglai Zhang ${ }^{2 * *}$ \\ ${ }^{1}$ Business School, Hohai University, Nanjing, China \\ ${ }^{2}$ Department of Chemistry, Henan University, Kaifeng, China
}

Received: 7 March 2019

Accepted: 24 July 2019

\begin{abstract}
As the key source for freshwater resources, urban rivers are essential for human survival and urban socio-economic development. Recently, the functions of urban rivers have been damaged by increasing human activities. A better understanding of the health state of urban rivers is the basis of sustainable urban planning. To this purpose, this research took the Jinshui River as a research area. An indicator system for urban river health evaluation was first established using the driving force-pressure-stateimpact-response (DPSIR) framework. The health state of the Jinshui from 2008 to 2017 was then assessed based on the urban river health index, which was calculated by the improved fuzzy matterelement extension model. The results show that the overall health status of the Jinshui has improved, from its unhealthy state in 2008-2016 to a sub-healthy state in 2017. Corresponding response measures have achieved certain results, which have led to an improvement in the health state of the river. However, its health still faced many problems, including pressure from a rapid urbanization rate and population density, a large amount of sewage discharge, and serious water pollution. In general, the health of the Jinshui was still on the low side. Therefore, to ensure sustainable water environment in the region, it is necessary to further govern the water environment and improve the health status of urban rivers. This research can help government easily understand an urban river's health state and formulate effective measures in the future.
\end{abstract}

Keywords: urban river, DPSIR framework, improved fuzzy matter-element extension model, health assessment, Jinshui River

*e-mail: kzzhang@hhu.edu.cn

**e-mail: zhangjinglai@henu.edu.cn 


\section{Introduction}

An urban river has an important value in human survival, since it can provide water resources for domestic life, industrial production and agricultural irrigation [1]. An urban river plays an important role in social and economic development. Unfortunately, along with large-scale urbanization and rapid industrialization, the health problems of urban rivers are increasingly prominent, which are mainly caused by human activities such as uncontrolled sewage discharge, unlimited water use, and sewage discharge [2-3]. The decline in ecological and social services functions of urban rivers has brough a serious negative impacts on the social sustainable development [4]. To improve the comprehensive function of an urban river and take protective measures more accurately, many government organizations and other stakeholders have begun to pay attention to evaluate a river's health [5-6]. The diagnosis of an urban rivers' health is the first step in the protection of urban rivers. Thus, it is of great practical significance to seek scientific evaluation methods to identify the health problems of urban rivers for urban sustainable development.

River health refers to a good good and stable state in which river's ecological functions and natural functions are not affected and can ensure socio-economic sustainable development [7]. Recently, two kinds of river health assessment methods have been popular. One is the biological monitoring method, which evaluates the river state by comparing the river's biological elements with or without human activity [8-10]. For example, the habitat evaluation of short rivers, with aquatic organisms as the object of assessment, was developed by the United States Environmental Protection Agency [11]. A comprehensive evaluation methodology was used by the Federal Water Unit of Germany to evaluate habitats for various types of rivers [12]. The River Invertebrate Prediction and Classification System (RIVPACS) was developed by the British Freshwater Ecology Institute to assess river health [13]. The other approach is the integrity index method, which is based on hydrology, ecology, socio-economic information and more [1416]. Xu et al. evaluated the Luanhe River's health state using the River Health Integrated Index [17]. Liu et al. developed an integrated index system to evaluate river health [18]. Yu et al. analyzed the river health state in an urbanized area by establishing the eco-hydrological indicators [19]. These integrity index methods that combine corresponding indicators with their own models can accurately evaluate river health.

These evaluation methods provide a reference for the evaluation of urban river health [20-22]. However, current studies about the evaluation of river health have some limitations. Some studies neglect the influence of human intervention on river health. Healthy rivers not only meet the functions of their own ecosystems, but also have the social service functions of water supply, water drain, and transportation. The rapid economic development and unsuitable human construction behaviors exert great pressure on urban rivers, which may lead to the development of river health toward an

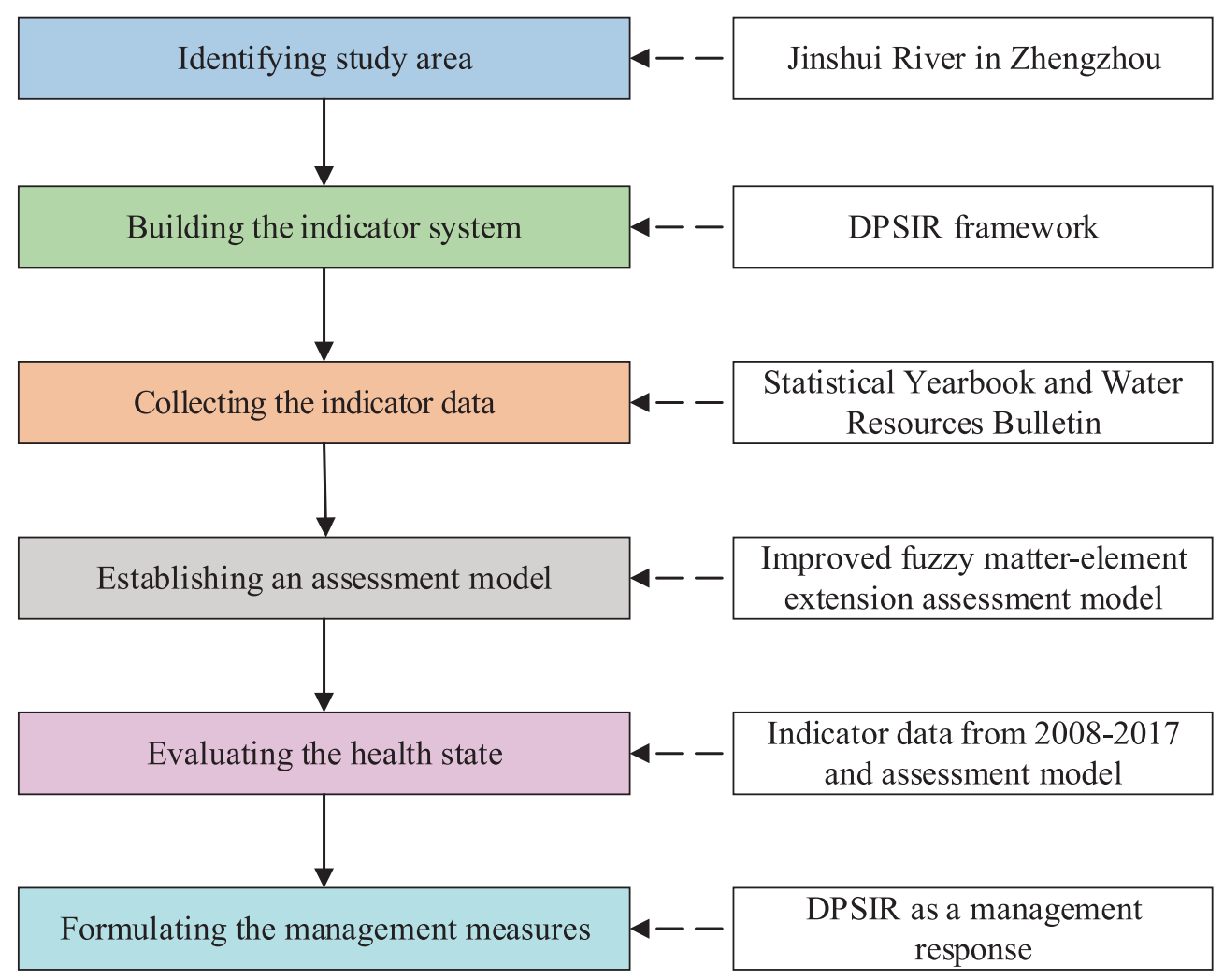

Fig. 1. Framework of the methodology in urban river health assessment. 
unfavorable direction. For this issue, a series of measures have been taken by local government organizations to protect the water ecological environment. Both positive and negative human intervention have an important impact on urban river health. But the two main methods for river health assessment ignore the positive human efforts to restore urban rivers. This neglect of positive human efforts in the process of assessing river health will lead to unscientific assessments and hinder the protection of urban rivers. Thus, it is necessary to make a full diagnosis of urban rivers health status by comprehensively considering the rivers' natural and social service functions, and the effects of human factors on river health.

To this purpose, first we established an indicator system for urban river health assessment according to the driving force-pressure-state-impact-response (DPSIR) framework. Secondly, we developed a comprehensive indicator that can reflect the health status of urban rivers, that is, urban River Health Index (RHI). can be determined by the improved Fuzzy Matter-Element Extension (FMEE) model. Finally, taking Jinshui River as a study case, we assessed the urban river health state. The current study can provide a basic reference for integrated urban river governance and protection.

\section{Material and Methods}

In this study, a systematic framework was developed to evaluate the health state of an urban river. The main steps of the research framework are as follows:

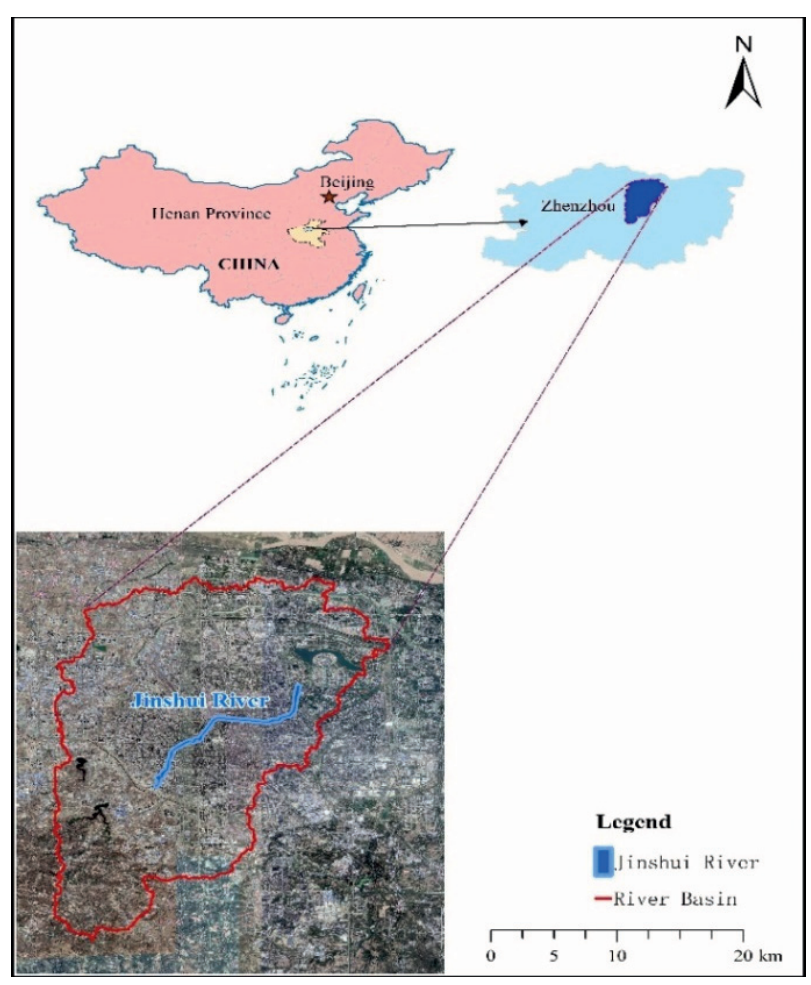

Fig. 2. Location of the Jinshui River.
(1) identifying the research region; (2) building the quantitative indicators system; (3) collecting the indicator data; (4) establishing the assessment model; (5) evaluating the health state; and (6) formulating the management measures. The framework of the methodology in urban river health assessment is shown in Fig. 1.

\section{Study Area}

The Jinshui River is located in Zhengzhou city, which is one of the main flood channels in Zhengzhou, Henan Province, China (Fig. 2). It originates from Meishan Mountain to the southwest and finally flows into the Jialu River. In total, the Jinshui is approximately 22.57 kilometers in length, and the width ranges from 3 to 7 meters. The Jinshui has a basin area of 102.4 square kilometers.

The average temperature of Jinshui River is 15.6 degrees Celsius, with a hot and dry summer and a cold and wet winter. As the oldest river in Zhengzhou, the Jinshui has a history of more than 1,000 years. It passes through Zhengzhou and flows from west to east. At present, the middle and lower reaches of the Jinshui are in Zhengzhou, and the upper reach is in the suburbs.

\section{Constructing an Indicator System}

The driving force-pressure-state-impact-response (DPSIR) framework was first proposed by the European Environmental Agency (EEA), which is widely used for analyzing environmental problems [23-24]. This framework evolves from the Pressure-State-Response (PSR) and Driving Force-State-Response (DSR) models, and has the advantages of flexibility, comprehensiveness, and integrity [25]. It includes natural, social and economic information and reflects the causal relationship between environmental health and a series of human activities at different scales. The DPSIR framework includes five subsystems: driving force, pressures, state, impacts, responses, which explores the interaction between humans and the environment [26-27].

The DPSIR framework of urban river health assessment fully reflects the internal motive force of regional economic development, pressures on urban rivers caused by social and economic development, the maintained state of the urban river, impact of urban river state to society, economy, and environment, and the human response. The DPSIR model framework of urban river health assessment is used to understand relationships and interactions between water environment and human activities in order to analyze the health status of the urban river. The DPSIR framework is shown in Fig. 3.

According to the DPSIR framework, the indicator system for urban river health evaluation is constructed. According to the related research findings [17, 28-33], the 24 evaluation indicators are determined in this study. Among them, the indicators (D1-D3) of 


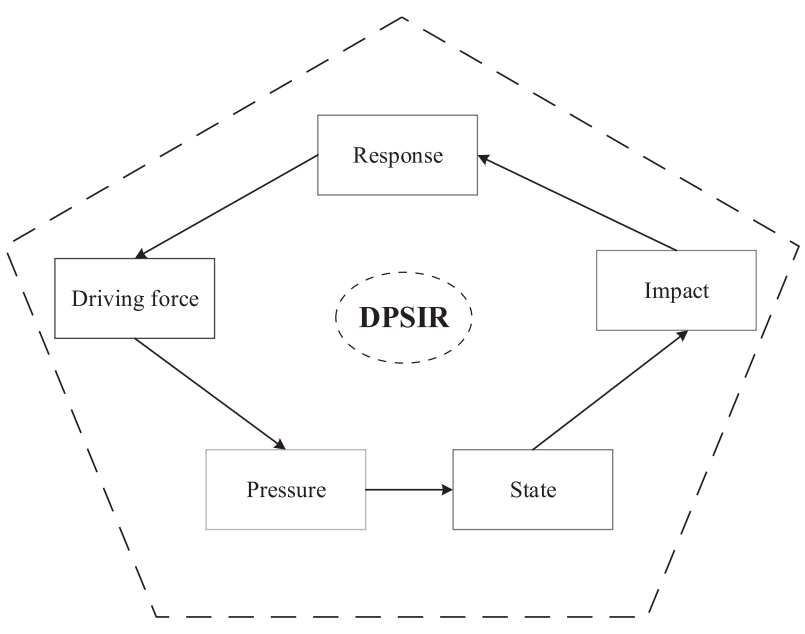

Fig. 3. DPSIR framework of urban river health assessment.

the driving force subsystem are mainly selected from the situation of regional urbanization. The indicators (P1-P5) of the pressure subsystem are mainly determined from the three aspects of economic development, water consumption and pollutant discharge in the area. The indicators (S1-S6) of the state subsystem are mainly selected based on the water environment state of an urban river. The indicators (I1-I4) of the impact subsystem are mainly determined from the effect of regional urbanization on river water resources. The indicators (R1-R6) of the response subsystem are mainly set from the corresponding protective measures taken by humans. As the health state of an urban river is not static and unchanged, determining the health grade for each indicator in the indicator system is needed. It is the standard for the health evaluation of an urban river. In this study, the grade standard of each indicator is determined based on the existing studies [34-37]. The indicator system for urban river health evaluation and the grade standard classification are shown in Table 1.

In the driving force subsystem, GDP growth rate (D1) reflects the internal force of economic development and environmental change; urbanization rate (D2) and population density (D3) reflect the internal force of regional development. In terms of the pressure subsystem, household water consumption (P1) reflects the pressure of domestic water consumption on an urban river; water consumption of industrial output (P2) reflects the pressure of economic development on urban river water resources; water consumption of agricultural output (P3) reflects the pressure of agricultural development on urban river water resources; COD emission (P4) and sewage discharge (P5) reflect the pollution discharge pressures on an urban river. Among the state subsystem, riparian vegetation coverage rate (S1) reflects the water environmental state; bank stability (S2) reflects the short-term state of the river slope protection; water quality compliance rate (S3) reflects the water quality state of the urban river; the phytoplankton Shannon index (S4) reflects the water quality state of the urban river; and the flood control guarantee rate (S5) and water supply guarantee rate (S6) reflect the social service function of the urban river. In the impact subsystem, rate of ecological water consumption (I1) reflects the impact of river water resources on the ecological environment; water resources amount per capita (I2) reflects the impact of river water resources on status of water resources amount per capita; and annual runoff (I3) and rate of standard river length (I4) reflect the impact of river water resources on water environment. In the response subsystem, wastewater treatment rate (R1) reflects the capacity of sewage treatment; rain and sewage diversion rate (R2) reflects the separation degree of rainwater and sewage; wetland preservation rate (R3) reflects the capacity of wetland protection; green space construction rate (R4) reflects the capacity of river ecological restoration; construction rate of ecological embankments (R5) reflects the strength of urban ecological restoration; and rate of river governance investment to GDP (R6) reflects the capacity of investment to urban river governance.

\section{Data Sources}

The indicator data related to social economy comes from Zhengzhou Statistical Yearbook (2008-2017) published by the Zhengzhou Statistics Bureau. The indicator data related to river water environment and hydrology is obtained from the River Basin Management Department of Zhengzhou City, Zhengzhou Water Resources Bulletin and Statistic Yearbook on the Environment (2008-2017). The sources of the indicators are shown in Table 2.

\section{Improved Fuzzy Matter-Element Extension Model}

Extenics is the basis of the FMEE model, which was first proposed by Cai Wen in 1983 [41]. The fuzzy matter-element analysis combines extenics with fuzzy mathematics to solve the incompatible complex problems in multi-indicator assessment [17]. The FMEE method is often used to assess environmental quality [42-43]. Urban river health is a complex and relative fuzzy concept, and the classification standards of the evaluation indicators are not the same. The FMEE method is considered to deal with incompatibility among the indicators. In the FMEE model, the weight value represents the relative importance degree of each assessment indicator in urban river health. As a method of objectively determining weights, the entropy method relies on mathematical theory to calculate the index weights. It can directly use the indicator value to calculate the weight, which effectively reflects the importance of the indicator [4445]. An urban river can be assessed using the improved FMEE extension model. Steps of this model are as follows [17, 42-43]: 


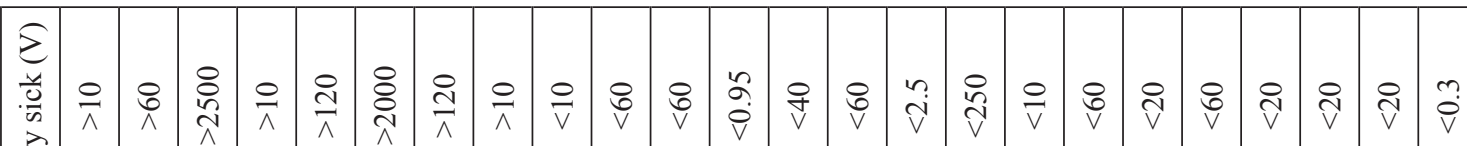
$\stackrel{\overrightarrow{0}}{>}$

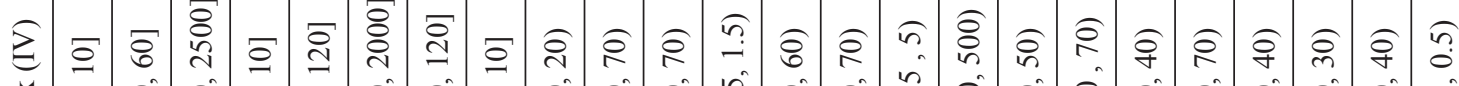
क

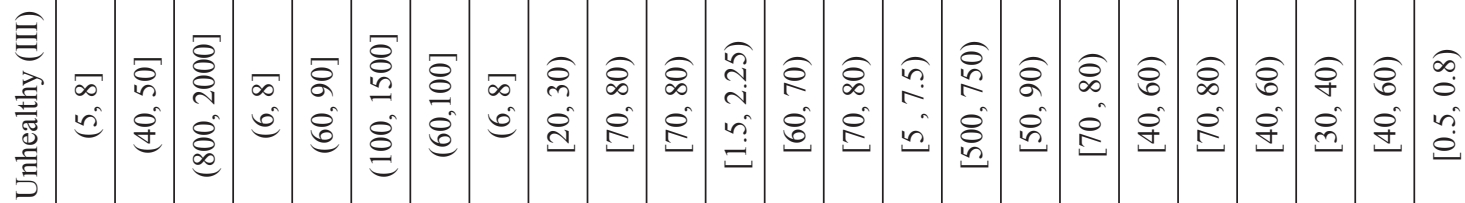

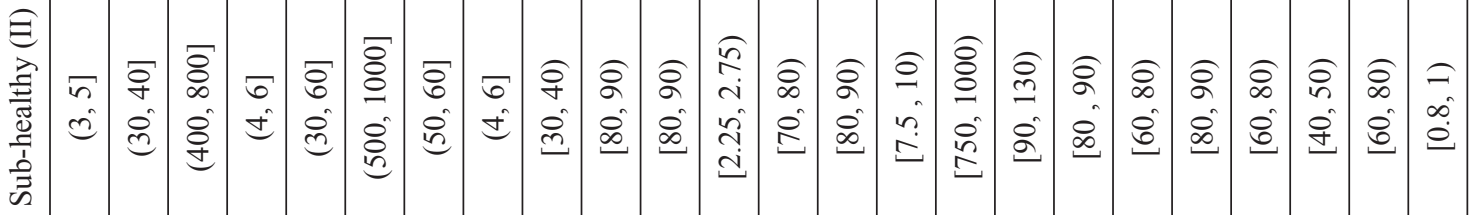

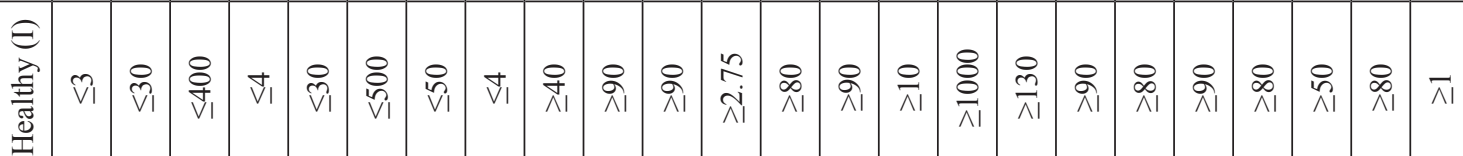

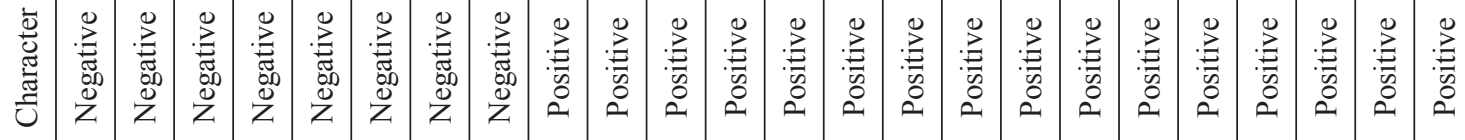

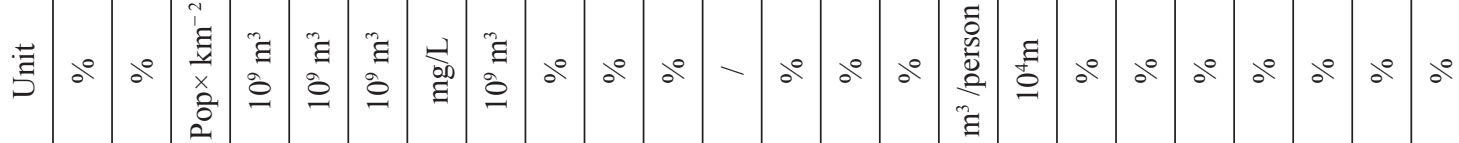

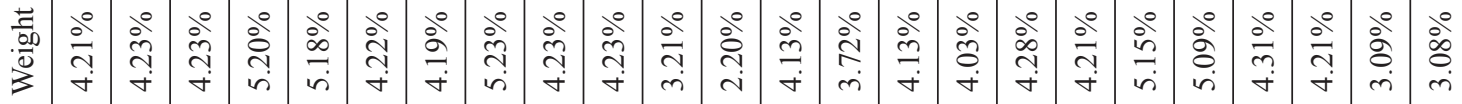

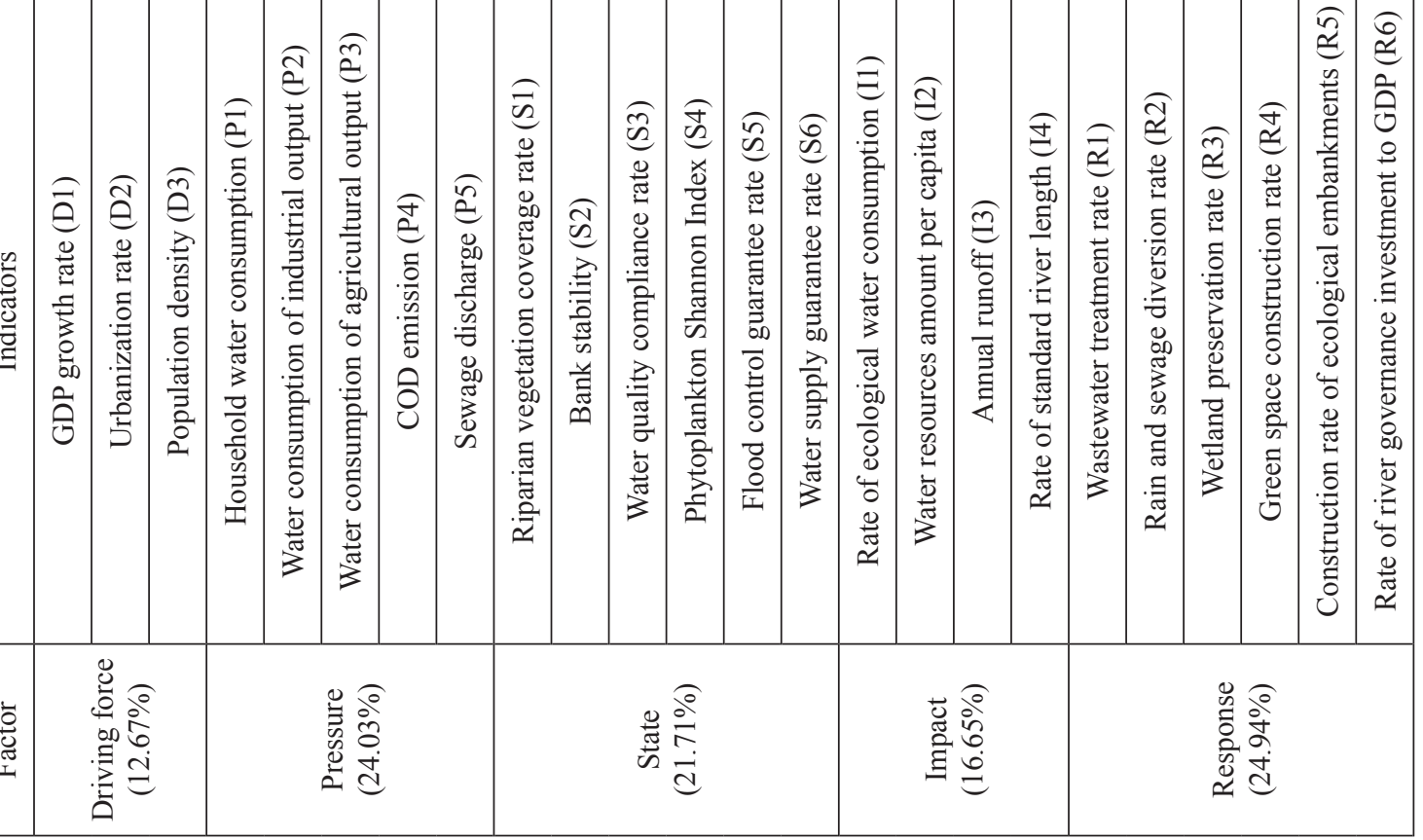


Table 2. Sources of the indicators.

\begin{tabular}{|c|c|}
\hline Indicator & Source \\
\hline $\begin{array}{c}\text { GDP growth rate (D1); Urbanization rate (D2); Population density (D3); Green space con- } \\
\text { struction rate (R4); Rate of river governance investment to GDP (R6). }\end{array}$ & $\begin{array}{c}\text { Zhengzhou Statistical Yearbook } \\
\text { (2008-2017) [38] }\end{array}$ \\
\hline $\begin{array}{c}\text { Household water consumption (P1); Water consumption of industrial output (P2); Water } \\
\text { consumption of agricultural output (P3); COD emission (P4); Sewage discharge (P5); Rate } \\
\text { of ecological water consumption (I1); Water resources amount per capita (I2); Annual runoff } \\
\text { (I3); Wastewater treatment rate (R1). }\end{array}$ & $\begin{array}{c}\text { Zhengzhou Water Resources Bulletin } \\
\text { (2008-2017) [39] }\end{array}$ \\
\hline Wetland preservation rate (R3); Construction rate of ecological embankments (R5). & $\begin{array}{c}\text { China Statistic Yearbook on } \\
\text { Environment (2008-2017) [40] }\end{array}$ \\
\hline $\begin{array}{c}\text { Riparian vegetation coverage rate (S1); Bank stability (S2); Water quality compliance rate } \\
\text { (S3); Phytoplankton Shannon Index (S4); Flood control guarantee rate (S5); Water supply } \\
\text { guarantee rate (S6); Rate of standard river length (I4); Rain and sewage diversion rate (R2). }\end{array}$ & $\begin{array}{c}\text { River Basin Management Department } \\
\text { of Zhengzhou City }\end{array}$ \\
\hline
\end{tabular}

(1) Calculate the indicator weight using the entropy method

(a) Non-dimensionalization data processing

Given the evaluation standards of indicators are inconsistent, it is necessary to convert the indicator values to dimensionless values, using the following normalization formula:

Positive indicators:

$$
t_{i j}=\left(x_{i j}-\min \left\{x_{i}\right\}\right) /\left(\max \left\{x_{i}\right\}-\min \left\{x_{i}\right\}\right)
$$

Negative indicators:

$$
t_{i j}=\left(\max \left\{x_{i}\right\}-x_{i j}\right) /\left(\max \left\{x_{i}\right\}-\min \left\{x_{i}\right\}\right)
$$

The proportion of the indicator $i$ in year $j$ :

$$
r_{i j}=t_{i j} / \sum_{j=1}^{n} t_{i j}
$$

...where $t_{i j}$ is the normalized value of $x_{i j}, i=1,2, \ldots, m$, $i=1,2, \ldots, n$ and $r_{i j}$ is the proportion of the indicator $x_{i j}$.

(b) Determine the information entropy:

$$
H_{i}=-\frac{1}{\ln n} \sum_{j=1}^{n} r_{i j} \ln r_{i j}
$$

...where $H_{i}$ is the information entropy of $x_{i}$.

(c) Calculate the indicator entropy weight.

$$
w_{i}=\frac{1-H_{i}}{m-\sum_{i=1}^{m} H_{i}}\left(0<w_{i}<1, \sum_{i}^{m} w_{i}=1\right)
$$

...where $w_{i}$ is the entropy weight of $x_{i}$.

(2) Establish the fuzzy matter-element of urban river health evaluation

According to matter-element analysis theory, any object to be evaluated can be represented by subject name $(S)$, assessment characteristics $(C)$, and measurement values $(x)$. Therefore, the fuzzy matterelement of urban river health evaluation $S$ can be represented by assessment characteristics $C_{1}, C_{2}, \ldots, C_{m}$, with measured values $x_{1}, x_{2}, \ldots, x_{m}$. refers to the number of the assessment characteristics $C$. The evaluation matrix $R$ of urban river health is:

$$
R=(S, C, X)=\left[\begin{array}{cccccc}
x_{11} & x_{12} & \cdots & x_{1 j} & \cdots & x_{1,10} \\
x_{21} & x_{22} & \cdots & x_{2 j} & \cdots & x_{2,10} \\
\vdots & \vdots & \vdots & & \vdots \\
x_{i 1} & x_{i 2} & \cdots & x_{i j} & \cdots & x_{i, n} \\
x_{24,1} & x_{, 24,2} & \cdots & x_{, 24, j} & \cdots & x_{24,10}
\end{array}\right]
$$

...where $S$ represents the urban river health state and $x_{i j}$ represents the measured value of assessment characteristics $C$.

(3) Determine the classical field $R_{P}$

$$
R_{p}=\left[\begin{array}{lll}
S_{P}, & C, & X_{i P}
\end{array}\right]=\left[\begin{array}{ccc} 
& c_{1} & x_{1 P} \\
& c_{2} & x_{2 P} \\
S_{P} & \vdots & \vdots \\
& c_{24} & x_{24 P}
\end{array}\right]=\left[\begin{array}{ccc}
c_{1} & \left(a_{1 P}, b_{1 P}\right) \\
c_{2} & \left(a_{2 P}, b_{2 P}\right) \\
S_{P} & \vdots & \vdots \\
& c_{24} & \left(a_{24 P}, b_{24 P}\right)
\end{array}\right]
$$

...where $X_{i}$ represents the critical threshold $\left(a_{i P}, b_{i P}\right)$ of the $i$ indicator, that is, the classical field.

(4) Determine the limited field $R_{M}$

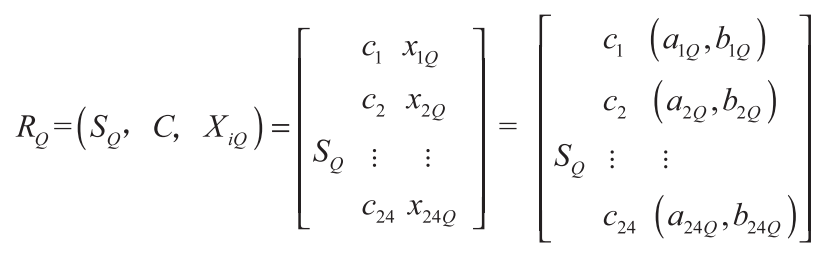

...where $S_{O}$ refers to the overall health state of the urban river; $X_{i Q}$ is the value range of the corresponding indicator $c_{1} ; a_{i Q}$ and $b_{i Q}$ represent the minimum value and the maximum value of the indicator $c_{1}$.

(5) Determine the improved correlation degree function

The correlation degree function of the traditional FMEE model is segmented, and it is inconvenient to 
calculate the correlation degree of each indicator. In addition, when the measured value of the indicator exceeds the range of the limited field, the correlation degree function of the traditional FMEE model cannot be used to calculate the correlation degree. In order to solve the above problems, an improved correlation degree function is defined. The correlation function can be expressed as follows [46]:

$$
k_{i j}\left(x_{i j}\right)=\frac{\frac{1}{2}\left(b_{i P}-a_{i P}\right)-\left|x_{i}-\frac{1}{2}\left(b_{i P}+a_{i P}\right)\right|}{\left(b_{i P}-a_{i P}\right)\left(b_{i Q}-a_{i Q}\right)}
$$

In the expression, $a_{i P}$ and $b_{i P}$ represent the lower and upper limits in the evaluation level $\mathrm{P}$, respectively [17].

(6) Calculate the $R H I$

$u R H I$ can be obtained according to the entropy weight of the indicator and the relation degree matrix. The RHI of urban river health assessment in the present study can be calculated by the following formula:

$$
\begin{aligned}
& R H I=\sum_{i=1}^{m} w_{i} k_{i j}\left(x_{i j}\right) \\
& R H I_{z}=\sum_{i=1}^{y} k_{i j z} \frac{w_{i z}}{\sum_{i=1}^{y} w_{i z}}
\end{aligned}
$$

...where $R H I$ is the integrated index of urban river health; $\mathrm{RHI}_{z}$ represents the corresponding subsystem integrated index, $z=1,2,, 3,4,5 ; k_{i j z}$ and $w_{i z}$ represent the relation degree and the weight of the corresponding subsystem indicators, respectively; and $y$ refers to the number of corresponding subsystem indicators.

\section{(7) Criterion of $R H I$}

The health state standard threshold of RHI can be obtained by the improved FMEE method, as follows:

$$
R H I=(S, C, X)=\left[\begin{array}{ccccc}
\text { I } & \text { II } & \text { III } & \text { IV } & \text { V } \\
0 & (0,0.312] & (0.312,0.631] & (0.631,1) & 1
\end{array}\right]
$$

According to this model, the standard classification of urban river health assessment was obtained, as shown in Table 3.

\section{Results and Discussion}

\section{Results of Entropy Weight}

According to Eqs (1)-(5), the weights of indicator system are obtained. The weight results of the indicator system are shown in Table 1. These five subsystems were ranked by their weight values (from highest to lowest) in the following way: response subsystem $(24.94 \%)>$ pressure subsystem $(24.03 \%)>$ state subsystem $(21.71 \%)$ $>$ impact subsystem $(16.65 \%)>$ driving force subsystem $(12.67 \%)$. These results show that the response subsystem has the largest weight value, which means that the positive response subsystem taken by the local government and NGOs has the greatest influence on the improvement of the health state of urban rivers. In addition, the pressure subsystem also plays a major role in the health state of the Jinshui River, with a weight of $24.03 \%$. In comparison, the weight value of the driving force $(12.67 \%)$ subsystem is the smallest, which implies that the driving force subsystem has a minimal effect on the health level in the Jinshui.

In terms of indicator layer, the indicators of water consumption of industrial output (5.18\%), household water consumption (5.20\%), and sewage discharge $(5.23 \%)$ are considered to exert the greatest influence on an urban river. These indicators all come from the pressure subsystem, meaning that household water consumption (P1), water consumption of industrial output (P2), and sewage discharge (P5) are the main sources of pressure on urban river health. These findings are consistent with the status quo, and suggest that in the process of urbanization in Zhengzhou and its rapid industrialization has brought greater pressure on urban rivers. Wastewater treatment rate (R1), rain and sewage diversion rate (R2) are considered to have the greatest influence on the response subsystem, a finding that emphasizes the importance of water environment restoration. The results of this study indicate that more attention should be paid to the response and pressure subsystems in protecting an urban river.

\section{Comprehensive Evaluation of Urban River Health}

According to Eqs (6) - (11), the results of RHI in the Jinshui from 2008 to 2017 were obtained. The results of RHI in the Jinshui are shown in Table 4. The health status of the Jinshui from 2008 to 2017 was diagnosed, which was determined by comparing the RHI of the river with the standard RHI.

The change trend of RHI in the Jinshu is provided in Fig. 4. Overall, except in 2011, RHI showed an

Table 3. Classifications of urban river health.

\begin{tabular}{|c|c|c|c|c|c|}
\hline Assessment level & Very sick & Sick & Unhealthy & Sub-healthy & Healthy \\
\hline RHI & 0 & $(0,0.312)$ & {$[0.312,0.631)$} & {$[0.631,1)$} & 1 \\
\hline
\end{tabular}


Table 4. Results of RHI in the Jinshui River from 2008 to 2017.

\begin{tabular}{|c|c|c|c|c|c|c|c|c|c|c|}
\hline \multirow{2}{*}{ System } & \multicolumn{10}{|c|}{ RHI } \\
\cline { 2 - 13 } & 2008 & 2009 & 2010 & 2011 & 2012 & 2013 & 2014 & 2015 & 2016 & 2017 \\
\hline $\mathrm{D}$ & 0.7616 & 0.8012 & 0.7877 & 0.7918 & 0.7956 & 0.7989 & 0.7744 & 0.8070 & 0.8066 & 0.7417 \\
\hline $\mathrm{P}$ & 0.4339 & 0.4354 & 0.4417 & 0.3722 & 0.4394 & 0.5423 & 0.5574 & 0.5534 & 0.5551 & 0.6423 \\
\hline $\mathrm{S}$ & 0.3621 & 0.4410 & 0.4827 & 0.4989 & 0.5870 & 0.6421 & 0.6848 & 0.7229 & 0.7770 & 0.8107 \\
\hline $\mathrm{I}$ & 0.3071 & 0.4450 & 0.4864 & 0.5010 & 0.5169 & 0.5722 & 0.5843 & 0.6181 & 0.6295 & 0.6729 \\
\hline $\mathrm{R}$ & 0.1686 & 0.2159 & 0.2335 & 0.3057 & 0.3638 & 0.4301 & 0.4794 & 0.6030 & 0.6326 & 0.6723 \\
\hline DPSIR & 0.3205 & 0.3559 & 0.3846 & 0.3781 & 0.4318 & 0.4882 & 0.5182 & 0.5680 & 0.5953 & 0.6341 \\
\hline
\end{tabular}

increasing trend from 0.32 in 2008 to 0.634 in 2017. This suggests that the health state of the Jinshui significantly improved between 2008 and 2017. The Jinshui was in an unhealthy state from 2008 to 2016, and in a sub-healthy state in 2017. In 2011, the value of RHI displayed a declining trend, which means that the health state in 2011 had declined. It is worth noting that the value of RHI has shown a clear growth trend in 2012. This is largely due to the water environment management department in Zhengzhou City increasing investment in water environmental governance in 2012. In the same year, the government implemented the corresponding measures of urban river governance and restoration. The emphasis of the local government on water environment governance plays an important role in improving the health status of urban rivers. However, the sub-healthy state means that the urban river cannot meet the basic needs for sustainable development.

\section{Evaluating a Different Subsystem}

The values of RHI in the five subsystems are calculated for the period of 2008-2017, which are listed in Table 4. The trends of the five subsystems' RHIs in the Jinshui are shown in Fig. 5, which demonstrates the health state of the five subsystems, showing an overall increasing trend during the surveyed period. Our analysis took five subsystems into account, examining the health states of driving force, pressure, state, impact and the response subsystems.

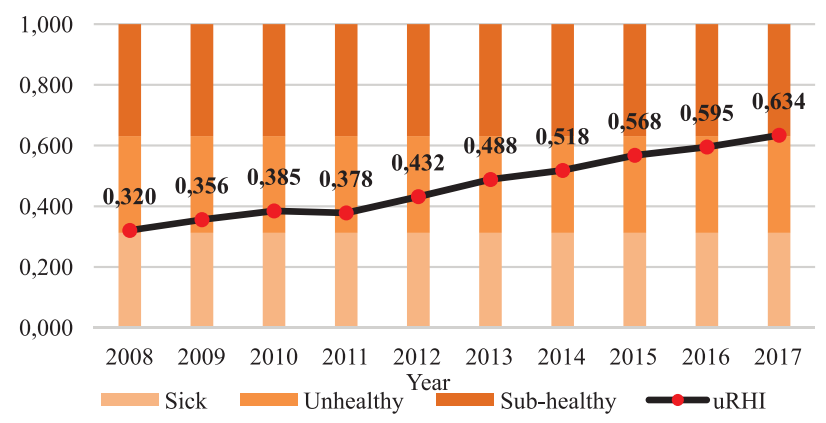

Fig. 4. RHI trends in the Jinshui River.
Although the urban river health index of driving force subsystem $R H I_{d}$ in the Jinshui showed a slightly declining trend, the downward trend is not clear. Overall, the driving force subsystem in the Jinshui remained a sub-healthy state from 2008 to 2017. It is worth nothing that the $R H I_{D}$ value displayed a clear decline in 2017, with the lowest $R H I_{d}$, which implies that the healthy state of the driving force subsystem deteriorated in 2017.

As shown in Fig. 5, the urban river health index of pressure subsystem $R H I_{P}$ value in the Jinshui has experienced large fluctuation. It initially increased slightly, subsequently clearly decreased from 2010 to 2011, and finally rose from 2011 to 2017. This means that the health state of the pressure subsystem has fluctuated over the past decade. The health state of the pressure subsystem was in an unhealthy state from 2008 to 2016 and in a sub-healthy state in 2017. This fluctuation is mainly attributed to the increased pressure on river health from urban development in 2011. As a whole, the values of $R H I_{p}$ showed an upward trend from 2008 to 2017. The overall health level of the pressure subsystem has improved; however, it was still low. It is mainly due to the great pressure brought by the rapid development of the socio-economy and continuous accelerated urbanization in Zhengzhou.

The urban river health index of state subsystem $\mathrm{RHI}_{\mathrm{S}}$ showed a clear upward trend from 0.362 in 2008 to 0.81 in 2017. The state subsystem was in an unhealthy state from 2008 to 2012, and then increased to a sub-healthy state in 2013-2017. This represents that the health state of the state subsystem of the Jinshui has improved. We can infer that the health state of this subsystem may become better in the next few years. In general, the health states of the ecological and social services functions have improved in the Jinshui.

Fig. 5 reveals an overall increasing trend in the health level of an impact subsystem during the period 2008-2017. In the past 10 years, the urban river health index of impact subsystem $R H I_{i}$ in each year showed different degrees of increase. The health state of the impact subsystem was in a sick state in 2008 before rising to an unhealthy state from 2009 to 2015, and finally reaching a state of sub-healthy from 2016 


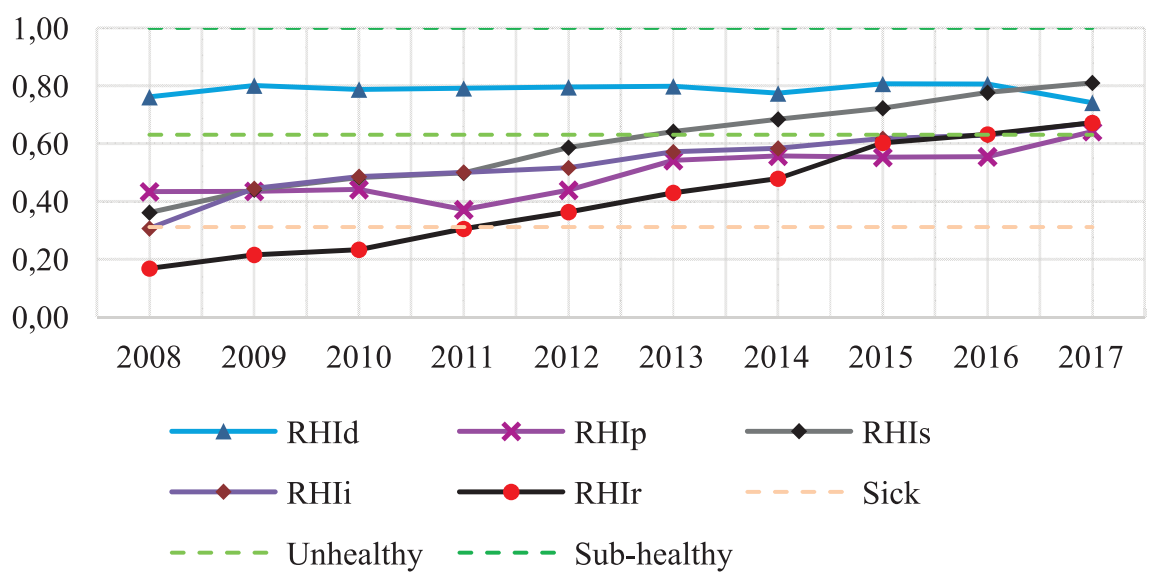

Fig. 5. RHI trend in five subsystems.

onwards. This indicates that the impact subsystem is trending in a more healthy direction.

Fig. 5 shows that we can see that the urban river health index of response subsystem $R H I_{r}$ has experienced a large increase. The health state of the response subsystem varied greatly, ranked as being in a sick state from 2008 to 2011 before rising to an unhealthy state from 2012 to 2015, and finally maintaining a sub-healthy state in 2017. In 2016, Zhengzhou began to implement urban construction of ecological civilization, and carried out large-scale environmental governance and rectification of 9 major rivers around the city. 2016 From the trends of the $R H I_{r}$, we can infer that the response measures are gradually making urban rivers healthier.

\section{Evaluating Different Indicators}

The indicators of urbanization rate (D2) and population density (D3) have an important impact on the health state of the driving force subsystem. They are all negative indicators, whereby the lager the value, the worse the river health state. Fig. 6. shows the trends of the two indicators in the driving force subsystem from 2008 to 2017. The indicator values of urbanization rate (D2) and population density (D3) showed a steady growth trend from 2008 to 2017. As the main negative influence indicators, the rising indicator values means that the accelerated urbanization and increased population brought a greater burden on the Jinshui in Zhengzhou, which has led to a decline in the health state of the driving force state.

The indicators of household water consumption (P1) and sewage discharge (P5) have an important impact on the health state of the pressure subsystem. Fig. 7. clearly shows the trend of the change in the key indicators in the pressure subsystem from 2008 to 2017 . The pressure subsystem basically was still low during the studied period for two main reasons:

1) Household water consumption (P1) showed a downward trend of fluctuation, but the health status of this indicator was not significantly improved. Specifically, household water consumption (P1) was in an unhealthy state from 2008 to 2010, while this indicator was in a very sick state from 2011 to 2012, followed by an unhealthy state from 2013 to 2017. The indicators of household water consumption (P4) reflect the pressure exerted by the higher demand for water due to domestic life.

2) The low health state of the pressure subsystem mainly due to the rapid industrialization and urbanization of these regions, which mainly rely on high water consumption and high-polluting industries. For

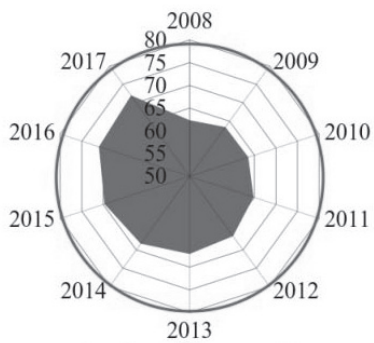

Urbanization rate (D2)

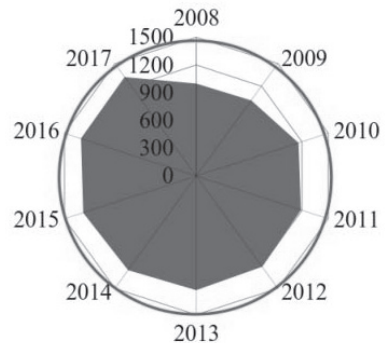

Population density (D3)

Fig. 6. Change trends of the key indicators in the driving force subsystem. 


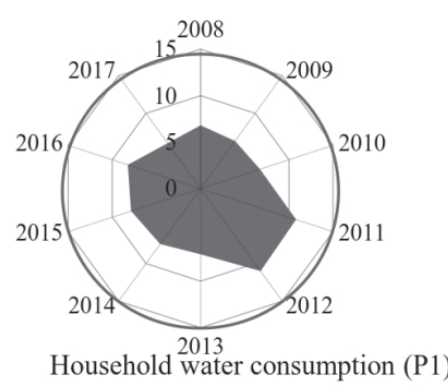

Fig. 7. Change trends of key indicators in the pressure subsystem.

example, the indicator of sewage discharge (P5) always was in a very sick state from 2008 to 2017 . The indicator values of sewage discharge (P5) were much higher than its health standards in the investigated period. A great amount of wastewater brought by industrial development added the burden on the Jinshui.

The indicators of riparian vegetation coverage rate (S1), bank stability (S2), flood control guarantee rate (S5), and water supply guarantee rate (S6) have a positive effect on the health state of the state subsystem. According to the characteristics of the indicators, they are positive indicators. The larger the indicator value, the healthier the state subsystem. The trends of the key indicators in the state subsystem from 2008 to 2017 are shown in Fig. 8. The health level of the state subsystem has improved in the Jinshui during the studied period for the following three reasons:

1) The indicator for riparian vegetation coverage rate (S1) displayed an upward trend of fluctuation, indicating an improved health state. Given that

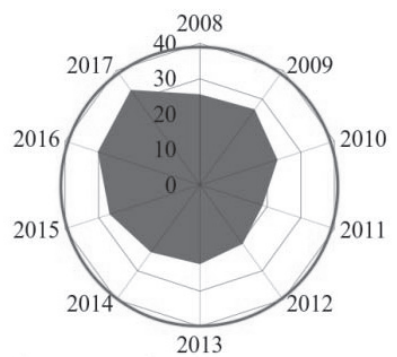

Riparian vegetation coverage rate (S1)

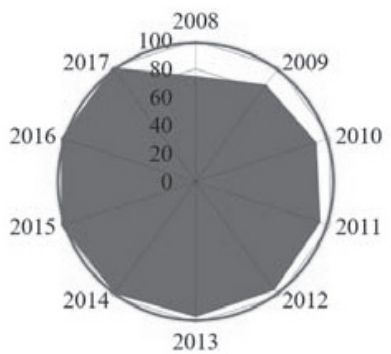

Flood control guarantee rate (S5)

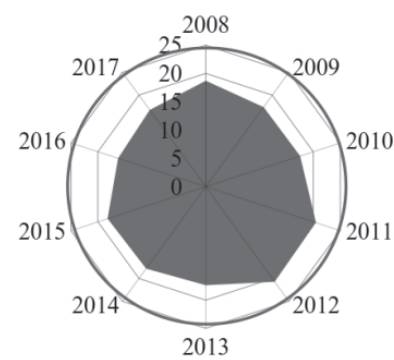

Sewage discharge (P5)

covered riparian vegetation can help improve the ability of a river to conserve water, the increasing indicator value of riparian vegetation coverage rate is considered to have a positive impact on river health.

2) Bank stability (S2) shows a clear and continued rate of growth, meaning an improved health state from a sick state to a healthy state. The stability of the river bank ensures the longitudinal continuity of the river. The increased bank stability is one of the main reasons for improved river health.

3) In terms of the social service function of an urban river, the indicator values of the flood control guarantee rate (S5) and water supply guarantee rate (S6) have been steadily increasing. The former indicator increased from a sub-healthy state to a healthy state, and the latter indicator increased from an unhealthy state to a healthy state. Flood control and water resources supply are the main social service functions of an urban river. The improved health state of the flood control and water supply can help ensure the effective functioning of the river

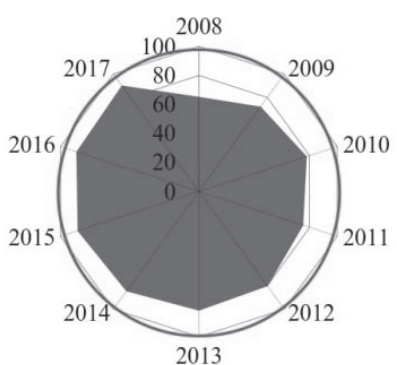

Bank stability (S2)

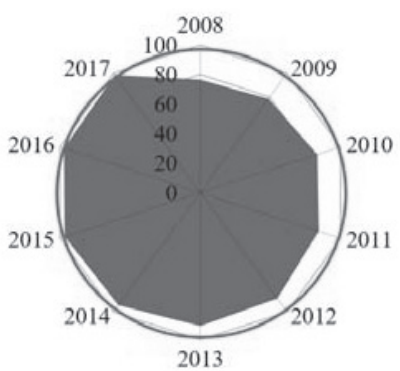

Water supply guarantee rate (S6)

Fig. 8. Change trends of the key indicators in the state subsystem. 


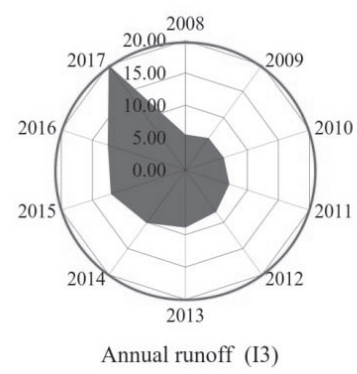

Fig. 9. Change trends of the key indicators in the impact subsystem.

social function.

The health state of the impact subsystem is directly affected by the indicators of annual runoff (I3) and rate of standard river length (I4). They are positive indicators. The trends of the two indicators in the impact subsystem from 2008 to 2017 are shown in Fig. 9. By observing the indicator values of annual runoff (I3), it's not difficult to see that the amount of runoff was increasing, which contributes to the improved health state of the impact subsystem. In addition, the indicator of the rate of standard river length shows an upward trend during the period 2008-2017. The rate of standard river length rose from $50 \%$ in 2007 to $80 \%$ in 2017 ; the health level changed from the sick state to the sub-healthy state in the past decade. The increase in the annual runoff and standard river length result in an improvement in the health status of the impact subsystem.

The indicators of wastewater treatment rate (R1), rain and sewage diversion rate (R2) have important effects on the health state of the response subsystem. According to the nature of these two indicators, the bigger the indicator value, the healthier the response subsystem. The trends of the two indicators in the response subsystem from 2008 to 2017 are shown in Fig. 10. The health level of the state subsystem has improved in the Jinshui during the studied period for the following reasons. The indicator values of the wastewater treatment rate (R1) and rain and sewage diversion rate (R2) showed a clear trend of growth. The early wastewater treatment and rain and sewage diversion rate were lower than the healthy level. However, along with the continuous development of

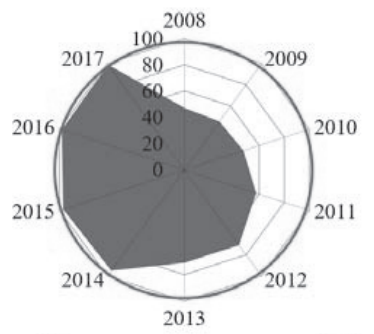

Wastewater treatment rate $(\mathrm{R} 1)$

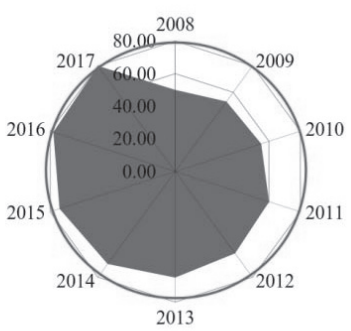

Rate of standard river length (I4)

advanced technology, the values of the two indicators were increasing in the later period, reaching a healthy state in 2017. The increased values of the two indicators contribute to the improvement of water quality. The increase in the two indicator values mean that the response measures of water ecological restoration in the river have been effective.

\section{Enlightenment for Urban River Management}

From the comprehensive evaluation results, it can be seen that both the overall health level and the subsystems' health state in the Jinshui have improved during the surveyed period. However, the overall health level is not high, and there is much room for improvement. To improve the health state of an urban river, integrated river basin management measures should be implemented by considering the DPSIR framework as the management factors.

According to the research findings, a policy guarantee system should be developed to support for the sustainable development between the urban economy and water environment protection. Moreover, the local government should focus on releasing the urban river's pressures. Given that sewage discharge has had an important effect on the pressure subsystem, the government can increase industrial water pollution control investments to control sewage discharge, thereby reducing the pressure of wastewater discharge on the river water environment. Also, by limiting the discharge of sewage to rivers and conducting river sewage interception projects to reduce the pressure of

Fig. 10. Change trends of the key indicators in the response subsystem.

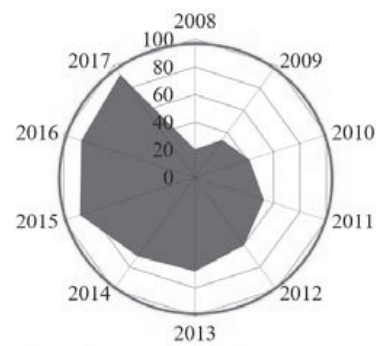

Rain and sewage diversion rate (R2) 
severe water environmental pollution on urban river health. In addition, the government can further increase investment to build green space, improving the health state of aquatic plants habitats and maintaining the stability of river ecosystems. As the rain and sewage diversion has a positive impact on the improvement of river water quality, it is necessary to further introduce advanced water environment governance technology and sewage treatment facilities in the process of urbanization development.

\section{Conclusions}

In view of the important role of urban rivers in human survival and economic development, it is necessary to develop urban river health assessment methods to provide a reference for sustainable urban planning. This paper assessed the health state of the Jinshui River from 2008 to 2017 based on the DPSIR framework and the improved FMEE model. Overall, the health status of the Jinshui has improved from 2008 to 2017. The river was unhealthy from 2008 to 2016, and in a sub-healthy state in 2017. From the perspective of each subsystem, the health levels of pressure, state, impact and response subsystems show an upward trend and have developed in a healthier direction, while the driving force subsystem has shown a downward trend. In general, the overall health level of the River is still low, and there is much room for improvement.

In conclusion, in the process of sustainable development in Zhengzhou, the government needs to continue to improve the health of the River. The urban river assessment method combining the DPSIR framework and the entropy FMEE model has a high application value. It can display the sources of driving force and pressures on the water environment, the factors of impact, and the effectiveness of the response measures, which can provide policy makers with a useful reference for river protection. This assessment methods provide more comprehensive technical support for urban rivers' protection and restoration.

\section{Acknowledgements}

This research was supported by project No. 71801130 from the National Natural Science Foundation of China, project No. 2018B714X14 supported by the Fundamental Research Funds for the Central Universities of China, and project No. KYCX18_0513 supported by the Foundation for the Postgraduate Research and Practice Innovation Program of Jiangsu Province.

\section{Conflict of Interest}

The authors declare no conflict of interest.

\section{References}

1. PEARCE M., WILLIS E., MAMEROE L., JORGENSEN B., MARTIN J. The prestige of sustainable living: implications for water use in Australia. Geographical Journal, 180 (2), 161, 2014.

2. MALMQVIST B., RUNDLE S. Threats to the running water ecosystems of the world. Environmental Conservation, 29 (2), 134, 2002.

3. ZIEGLER A.D., SHELFFIELD J., MAURER E.P. Detection of Intensification in Global- and ContinentalScale Hydrological Cycles: Temporal Scale of Evaluation. Journal of Climate, 16 (3), 535, 2003.

4. MA D., LUO W., YANG G., LU J., FAN Y. A study on a river health assessment method based on ecological flow. Ecological Modelling, 401, 144, 2019.

5. ROTT E., PIPP E., PFISTER P. Diatom methods developed for river quality assessment in Austria and a cross-check against numerical trophic indication methods used in Europe. Algological Studies, 110 (1), 91, 2003.

6. ZHAI X., ZHANG Y., WANG X., XIA J., LIANG T. Nonpoint source pollution modelling using Soil and Water Assessment Tool and its parameter sensitivity analysis in Xinl"anjiang catchment, China. Hydrological Processes, 28 (4), 1627, 2014.

7. MEYER J.L. Stream health: incorporating the human dimension to advance stream ecology. Journal of the North American Benthological Society, 16 (2), 439, 1997.

8. SMITH M.J., KAY W.R., EDWARD D.H.D., PAPAS P.J., RICHARDSON K.S.J., SIMPSON J.C. AusRivAS: using macroinvertebrates to assess ecological condition of rivers in Western Australia. Freshwater Biology, 41 (2), 269, 2010.

9. SYLVAIN D., STATZNER B. Invertebrate traits for the biomonitoring of large European rivers: an assessment of specific types of human impact. Freshwater Biology, 53 (3), 617, 2008.

10. SCHOFIELD N.J., DAVIES P.E. Measuring the health of our rivers. Water, 5 (6), 39, 1996.

11. WATER U.S.E.P. Rapid Bioassessment Protocols for Use in Wadeable Streams and Rivers: Periphyton, Benthic Macroinvertebrates, and Fish. United States Environmental Protection Agency, 1999.

12. KAMP U., BINDER W., HOLZL K. River habitat monitoring and assessment in Germany. Environmental Monitoring and Assessment, 127 (1-3), 209, 2007.

13. CLARKE R.T., WRIGHT J.F., FURSE M.T. RIVPACS models for predicting the expected macroinvertebrate fauna and assessing the ecological quality of rivers. Ecological Modelling, 160 (3), 219, 2003.

14. LADSON A. R. Development and testing of an Index of Stream Condition for waterway management in Australia. Freshwater Biology, 41 (2), 453, 1999.

15. BRIERLEY G., REID H., FRYIRS K., TRAHAN N. What are we monitoring and why? Using geomorphic principles to frame eco-hydrological assessments of river condition. Science of the Total Environment, 408 (9), 2025, 2010.

16. TINER R.W. Remotely-sensed indicators for monitoring the general condition of "natural habitat" in watersheds: an application for Delaware's Nanticoke River watershed. Ecological Indicators, 4 (4), 1, 2004.

17. XU W., DONG Z., HAO Z. LI D. River health evaluation based on the Fuzzy matter-element extension assessment model. Polish Journal of Environmental Study, 26 (3), 1353, 2017. 
18. LIU Q., DONG Z., XU W., FU X., TAN J., CHEN X., YANG G. Health Assessment of Luanhe River Based on Fuzzy Matter-element Model. Water Resources and Power, 32 (9), 47, 2014.

19. YU Z., XU Y., ZHANG Y., DENG X. Assessment of river health in urbanized area based on entropy weight and matter element model: A case study in Huzhou city at different stages of urbanization. Acta Scientiae Circumstantiae, 34 (12), 3188, 2014.

20. DENG X., XU Y., HAN L., YU Z., YANG M., PAN G. Assessment of river health based on an improved entropybased fuzzy matter-element model in the Taihu Plain, China. Ecological Indicators, 57, 8, 2015.

21. ZHAO Y., YANG, Z. Integrative Fuzzy Hierarchical Model for river health assessment: A case study of Yong River in Ningbo City, China. Communications in Nonlinear Science and Numerical Simulation, 14 (4), 1732, 2009.

22. PETESES M.L, SIQUEIRA-SOUZA F.K., FREITAS C. Selection of reference lakes and adaptation of a fish multimetric index of biotic integrity to six amazon floodplain lakes. Ecological Engineering, 97, 535, 2016.

23. LU W., XU C., WU J. Ecological effect assessment based on the DPSIR model of a polluted urban river during restoration: A case study of the Nanfei River, China. Ecological Indicators, 96, 146, 2019.

24. ROSIGLEYSE C.S., PEREIRA L.C.C., TRINDADE W.N., INGRID P. Application of the DPSIR framework to the evaluation of the recreational and environmental conditions on estuarine beaches of the Amazon coast. Ocean \& Coastal Management, 149 (15), 96, 2017.

25. KAGALOU I., LEONARDOS I., ANASTASIADOU C. The DPSIR Approach for an Integrated River Management Framework. A Preliminary Application on a Mediterranean Site (Kalamas River -NW Greece). Water Resources Management, 26 (6),1677, 2012.

26. BELL S. DPSIR $=$ A Problem Structuring Method? An exploration from the "Imagine" approach. European Journal of Operational Research, 222 (2), 350, 2012.

27. MALEKMOHAMMADI B., JAHANISHAKIB F. Vulnerability assessment of wetland landscape ecosystem services using driver-pressure-state-impact-response (DPSIR) model. Ecological Indicators, 82, 293, 2017.

28. FENG Z., ZHANG J., WU R., MA Q. Y. Ecosystem health assessment based on DPSIRM framework and health distance model in Nansi Lake, China. Stochastic Environmental Research \& Risk Assessment, 30 (4), 1235, 2016.

29. XIA T., ZHU W., XIN P., LI L. Assessment of urban stream morphology: an integrated index and modelling system. Environmental Monitoring and Assessment, 167 (1-4), 447, 2010.

30. ZHAO C., PAN T., DOU T., LIU J., LIU C., GE Y., ZHANG Y., YU X. Making global river ecosystem health assessments objective, quantitative and comparable. Science of the Total Environment, 667, 510, 2019.
31. SINGH P. K., SAXENA S. Towards developing a river health index. Ecological Indicators, 85, 999, 2018.

32. PINTO U., MAHESHWARI B. A framework for assessing river health in peri-urban landscapes. Ecohydrology \& Hydrobiology, 14 (2), 121, 2014.

33. JIA Y. Z., SHEN J. Q., WANG H., DONG G. H., SUN F. H. Evaluation of the spatiotemporal variation of sustainable utilization of water resources: Case Study from Henan Province (China). Water, 10 (5), 554, 2018.

34. ZHANG S., FAN W., YI Y., ZHAO Y., LIU J. Evaluation method for regional water cycle health based on naturesociety water cycle theory. Journal of Hydrology, 551, 352, 2017.

35. DONG G.H., SHEN J.Q., JIA Y.Z., SUN F.H. Comprehensive Evaluation of Water Resource Security: Case Study from Luoyang City, China, Water, 10 (8), 1106, 2018.

36. GROWNS I., ROURKE M., GILLIGAN D. Toward river health assessment using species distributional modeling. Ecological Indicators, 29, 138, 2013.

37. AMORES M.J., MENESES M., PASQUALINO J. Environmental assessment of urban water cycle on Mediterranean conditions by LCA approach. Journal of Cleaner Production, 43, 84, 2013.

38. Zhengzhou Statistics Bureau. Zhengzhou Statistical Yearbook; China Statistics Press: Beijing, China, 2017.

39. Water Resources Department of Henan. Zhengzhou Water Resources Bulletin; Water Resources Department of Henan: Zhengzhou, China, 2017.

40. National Bureau of Statistics of China; Ministry of Environmental Protection of China. China Statistic Yearbook on Environment, China Statistica Press: Beijing, China, 2017.

41. CAI W. Extension theory and its application. Chinese Science Bulletin, 44 (17), 1538, 1999.

42. LIU B., SUN F. H. Research on the Risk Assessment Method of PPP Project based on the Improved Matter Element Model, Scientia Iranica, 2019.

43. HAN H., LI H. M., ZHANG K. Z. Urban water ecosystem health evaluation based on the improved fuzzy matterelement extension assessment model: case study from Zhengzhou City, China. Mathematical Problems in Engineering, 2019, 1, 2019.

44. XIE T., WANG M., SU C., CHEN W. Evaluation of the natural attenuation capacity of urban residential soils with ecosystem-service performance index (EPX) and entropy-weight methods. Environmental Pollution, 238, $222,2018$.

45. ZOU Z., YUN Y. SUN J. Entropy method for determination of weight of evaluating indicators in fuzzy synthetic evaluation for water quality assessment. Journal of Environmental Science, 18, 1020, 2006.

46. YANG B., WANG Z., HU X. Performance Assessment and Impact Factors of Land Consolidation Project Based on Improved Extension Matter-element Model. China 
